https://helda.helsinki.fi

\title{
Screening Methods in Archaeology
}

\section{Lorenzon, Marta}

Springer International Publishing AG

2018

Lorenzon, M 2018 , Screening Methods in Archaeology . in C Smith (ed.), Encyclopedia of Global Archaeology . Springer International Publishing AG , Cham . https://doi.org/10.1007/978-3-319-51726-1_252

http://hdl.handle.net/10138/319557

https://doi.org/10.1007/978-3-319-51726-1_2520-1

Downloaded from Helda, University of Helsinki institutional repository.

This is an electronic reprint of the original article.

This reprint may differ from the original in pagination and typographic detail.

Please cite the original version. 


\title{
SCREENING METHODS IN ARCHAEOLOGY
}

\author{
Marta, Lorenzon \\ Centre of Excellence in Ancient Near Eastern \\ Empires, Department of Cultures, University of \\ Helsinki, \\ Helsinki, Finland \\ marta.lorenzon@helsinki.fi
}

\section{Introduction}

Screening methods are a relevant component of excavation methodology and are nowadays included in most fieldwork experiences. Archaeological excavations are destructive actions, consequently it is of utmost importance to devise procedures that help to recover the higher amount of ecofacts and artefacts. The recovery of all possible finds is fundamental to avoid bias in the consequent analysis of the site.

Screening methods have been part of the archaeological discourse for the last 60 years and focus on the analysis of the removed sediments in order to recover smaller artefacts, usually missed during excavation. The methodology varies and can be divided into dry screening (or sieving) and wet screening, implemented by water.

\section{Definition}

Screening methods consist of analysing the soil removed doing excavation through screen meshes of different size. This technique allows to recover artefacts and ecofacts, which are usually overlooked during the removal of the sediments due to their negligible size. Screening the soil directly impacts the amount of material that can be recovered and help avoiding bias during sample collection (Balme and Paterson 2014: 262-268; Hester, Shafer and Feder 2016: 93-97; Renfrew and Bahn 2016: 177).

The screening is conducted through a mesh fixed on a rectangular screen box characterized by an open top. The screen box can be made of wood or metal and can be manufactured in different sizes depending on the amount of sediments to be processed (Figure 1).

The screening is often set up in the proximity of the digging area in order to facilitate the movement of soil from the actual excavation with buckets or wheelbarrows. Once brought to the screening area, the sediment is poured on top of the screen box, which is then shaken, manually or mechanically, to separate fine and coarse fractions as this latter usually includes the overlooked artefacts and ecofacts. The fine fraction of the sediments passes through the mesh, thus leaving the coarse fraction resting on top of it.

Hence, the choice of mesh size is particularly important and depends on the local geology of the site. For instance, a too fine mesh would not allow small pebbles to pass through and can be problematic in fluvial contexts, where sediments are mainly made of gravel.

Traditionally, four mesh size are used in the fields, $1 / 2$ inch, $1 / 4$ inch, $1 / 8$ inch and 1/16 inch (or $12.7 \mathrm{~mm}$, $6.35 \mathrm{~mm}, 3.1 \mathrm{~mm}$ to $1.5 \mathrm{~mm}$ ), but they are not exclusive and other sizes can be employed. In order to understand which mesh is required at any given site, a pilot sampling is often carried out, in which the sediments are initially screened through a fine mesh to determine the size required for that specific deposit (Connor 2007: 37-38; Reitz and Shackley 2012: 84).

Screening methods can be divided into two diverse techniques: dry and wet screening.

Dry screening is the sieving of sediments through a mesh and requires the soil to pass dry through the mesh.

The mesh frame is suspended and can be positioned on legs or handheld. Sediments pass through the screens 
by shaking the mesh mechanically with a motor, or simply manually when the mesh is operated by one or two people (Maschner and Chippindale 2005: 142-144).

On the other hand, wet screening consists of using water to help the sediments through the mesh. The running water is poured on top of the screen to help the soil positioned on top of the screen box to pass through it. Once the fine fraction passes through, artefacts and ecofacts left on the screen are retrieved and dried before being archived. While this method is efficient, it can also be problematic for sites located in an arid environment or sites that do not have easily access to water sources to implement wet screening (Balme and Paterson 2014: 265, 293). Additionally, even though they share similar goals as identifying overlooked ecofacts, wet screening should not be confused with flotation, which follows a different methodology based on the density of the archaeobotanical remains (Renfrew and Bahn 2016: 244-250).

Both screening methods, dry and wet screening, can also be employed with a greater degree of accuracy in the laboratory environment during the post-excavation study period. Often soil samples from specific contexts (context samples) are packed and analysed at a later date to answer specific research questions (see entry on Excavation methods in archaeology entry at https://link.springer.com/referenceworkentry/10.1007/978-14419-0465-2_1494).

The choice between dry and wet screening is directly contingent to the type of sediment. For instance, wet silty-clayish soil can be particularly difficult to dry screen and often required water in order to break down clay bumps, separate the sediments from the artefacts and move it through the screen (Balme and Paterson 2014: 262-264; Maschner and Chippindale 2005: 143). Some systems of screening involve the use of multiple screen boxes positioned on top of each other with different mesh size to increase the finesse of the analysis (Hester, Shafer and Feder 2016: 93-97).

Finally, once the residue (i.e. artefacts and ecofacts) has been collected by dry or wet screening, it is sorted by separating bones, pottery fragments, shells, archaeobotanical remains, charcoals and eventual other finds to proceed with specialist analysis (Balme and Paterson 2014: 262-264).

\section{Key Issues/Current Debates/Future Directions/Examples}

The choice of appropriate screening techniques is of essential importance in order not to negatively affect the recovery of finds (Hageman and Goldstein 2009; Reitz and Shackley 2012: 83; Shaffer 1992; Shaffer and Sanchez 1994). This major issue relies on three cardinal points: 1 . there is not a "one and only" screening method that can be applied to every site; 2 . screening technique should be consistent within the same excavation; 3. the methodology selected should offer to all finds the same likelihood to be recovered (Balme and Paterson 2014: 262-264; Reitz and Shackley 2012: 83-84; Watson 1972).

Thus, the analysis of the site matrix is essential to determine which screening techniques should be implemented at each site to recover all the cultural and environmental finds (Hageman and Goldstein 2009; Reitz and Shackley 2012: 85). Ingbar's investigation (1985) tests the efficiency of diverse screening methods and indicates dry screening as more effective than wet screening, while dealing with sandy deposits since it allows for a more efficient recovery of finds. On the other hand, numerous studies indicate that clayish soils often require water to uncover finds, and recovery percentages are negatively affected by dry sieving (Burke, Smith and Zimmerman 2009: 170; Pearsall 2000: 18-22; Reitz and Shackley 2012: 86).

In the best-case scenario, different techniques should be tested and implemented based on the type of sediments (e.g. prevalence of clayish, loamy or sandy soil) as soil types clearly influence the choice of recovery method. Furthermore, they have a direct impact on the density of finds uncovered and their successive interpretation.

Likewise, the selection of mesh size deeply affects the recovery of artefacts as the choice of the wrong mesh may alter quantitatively the amount of micro-fauna recovered (Orton 2000: 164-165). Sapir-Hen et al. (2017) illustrates this key issue through a well-designed case study at Dor, presenting the impact on the archaeologists' interpretation when the percentage of macro-fauna vs micro-fauna highly varies based on distinct mesh sizes and techniques. In this case the fluctuation in finds' density results may be attributed 
equally to different techniques, diverse mesh size, or altered patterns of human behaviour present at the site. Therefore, this ambiguity should be discussed in the publication and acknowledged as a relevant factor affecting the archaeologist interpretation (Sapir-Hen et al. 2017).

Additionally, while the main aim of selecting the right screening method or mesh size is to drastically reduces the prejudice on collecting artefacts and ecofacts, there are still bias to be considered in the subsequent analysis and interpretation established by the sampling strategy carried out during excavation (Pearsall 2000: 112-116; Reitz and Shackley 2012: 88-91; Shaffer 1992). If not all the excavated deposits undergo screening, soil sampling - and the rationale behind it- becomes essential to understand contexts, occupational levels and findings. Sampling rationale involves multiple factors such as prior knowledge of the area, representativeness and accessibility (Hester, Shafer and Feder 2016: 25-39; Pearsall 2000: 69-71). These factors have a direct effect on the method's reliability and accuracy, and need also to be acknowledge when interpreting the finds. Consequently, the methodology used and the eventual sampling rationale, should be clearly stated in the final report to recognise and consider possible prejudices on the interpretation of the excavation materials.

Another noteworthy issue connected to screening methods deals with the treatment of fragile materials as these can be negatively affected by recovery techniques. For instance, careless screening can easily damage fragile ecofacts and artefacts as shells and bones can be broken when forcefully hit by stones during sieving, or painted artefacts (e.g. plaster, pottery) can be damaged by water during wet screening. Thus, screening should be carefully implemented with sediments that presents an abundance of these type of cultural and environmental finds (Balme and Paterson 2014: 326; Hester et al. 2016: 93; Reitz and Shackley 2012: 85).

A secondary problem in outlining screening methods is to clarify the difference between wet screening (or water screening) and floatation as the two methods fulfil different purposes (Maschner and Chippindale 2005: 779-781; Pearsall 2000: 15-29). Flotation is not usually performed on the integral excavation, but only on selected samples to help recovering archaeobotanical finds (seeds, plant remains, pieces of wood charcoal) (Renfrew and Bahn 2016: 244-250; Pearsall 2000: 15-29). It consists of immerging a soil sample contained in a mesh, or catch sieve, inside a body of water, which is then shaken to separate light density materials. Various typologies of floating devices are currently used in archaeology (Wagner 1988; Pearsall 2000: 15-20).

Finally, screening is a time-consuming techniques and excavation expediency often requires to work out a balance between methodological accuracy and efficiency (Burke, Smith and Zimmerman 2009: 167; Reitz and Shackley 2012: 89). For instance, large scale excavations need to consider that all the excavated contexts should receive the same level of screening and this latter task often requires multiple people assigned to it. Alternatively, a sample strategy can be implemented but it requires to be well-designed in advance and stating clearly the screening rationale and its impact on post-excavation analysis and publication of the results (Hageman and Goldstein 2009; Ingbar 1985; Sapir-Hen et al. 2017; Quitmyer 2004).

\section{Cross-References}

Field Method in Archaeology: Overview

Recording in Archaeology

Soil Pollen Analyses in Environmental Archaeology

Excavation Methods in Archaeology

Environmental Reconstruction in Archaeological Science 


\section{References}

Balme, J., and Paterson, A. 2014. Archaeology in practice: A student guide to archaeological analyses. Malden, MA: Wiley Blackwell.

Burke, H., Smith, C., and Zimmerman, L. J. 2009. The archaeologist's field handbook. Lanham: Altamira Press.

Connor, M. A. 2007. Forensic methods: Excavation for the archaeologist and investigator. Lanham, MD: Altamira Press.

Hageman J.B., and Goldstein, D.J. 2009. An integrated assessment of archaeobotanical recovery methods in the Neotropical rainforest of northern Belize: flotation and dry screening. In Journal of Archaeological Science, Volume 36, Issue 12, pp. 2841-2852.

Hester, T. R., Shafer, H. J., and Feder, K. L. 2016. Field methods in archaeology. Abingdon, Oxon: Routledge.

Ingbar E. 1985. A comparison of small-scale recovery techniques. In the Archaeology of Hidden cave, Nevada edited by D.H. Thomas, Anthropological papers 62, American Museum of Natural History New York, pp.7480

Maschner, H., and Chippindale, C. 2005. Handbook of archaeological methods. Lanham, Md.; Oxford: AltaMira Press.

Orton, C. 2000. Sampling in archaeology. Cambridge, UK: Cambridge University Press.

Pearsall, D.M. 2000. Paleoethnobotany: a handbook of procedures, New York: Academic Press.

Quitmyer, I. R. 2004. What Kind of Data are in the Back Dirt? An Experiment on the Influence of Screen Size on Optimal Data Recovery. Archaeofauna 13. Special Issue: Tropical Zooarchaeology, K. F. Emery and W.G. Teeter (eds.), pp. 109-129.

Reitz E.J., and Shackley M. 2012. Research Designs and Field Methods. In: Environmental Archaeology. Manuals in Archaeological Method, Theory and Technique. Springer, Boston, MA

Renfrew, C., and Bahn, P. G. 2016. Archaeology: Theories, methods, and practice. London: Thames and Hudson

Sapir-Hen, L., Sharon, I., Gilboa, A., and Dayan, T. 2017. Wet sieving a complex: Implications for retrieval protocols and studies of animal economy in historical periods, Journal of Archaeological Science, Volume 82, 2017, pp. $72-79$

Shaffer, B. S. 1992. Quarter-Inch Screening: Understanding Biases in Recovery of Vertebrate Faunal Remains. In American Antiquity, 57(1), 129-136. doi:10.2307/2694839

Shaffer, B. S., and Sanchez, J. L. J. 1994. Comparison of 1/8"- and 1/4"-mesh recovery of controlled samples of small-to-medium-sized mammals. American Antiquity, 59, pp. 525-530.

Wagner G. 1988. Comparability among recovery techniques. In C.A. Hastorf, V.S. Popper (Eds.), Current Paleoethnobotany: Analytical Methods and Cultural Interpretations of Archaeological Plant Remains, Chicago: University of Chicago Press, pp. 17-35

Watson, P. J. 1972. Fragmentation analysis of animal bone samples from archaeological sites. Archaeometry, 14, pp. 221-228. 


\section{Figure Captions}

Figure 1. Screening box. (Image: M. Lorenzon)

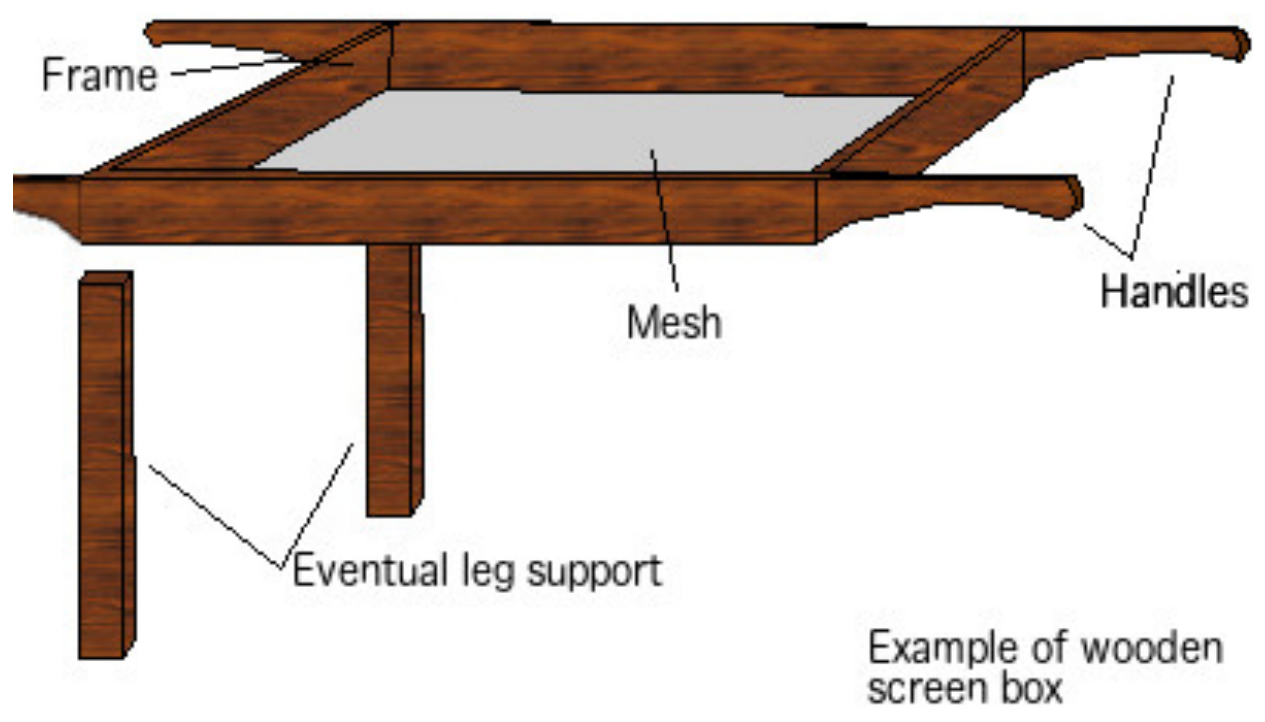

